\title{
Análise da capacidade combinatória em cruzamentos dialélicos de três cultivares de jiloeiro ${ }^{1}$.
}

\author{
Ana Cristina P.P. Carvalho ${ }^{2}$; Raul L.D. Ribeiro ${ }^{3}$ \\ ${ }^{2}$ PESAGRO-RIO, 23.851-970 Itaguaí-RJ. E-mail: eei@domain.com.br ${ }^{3}$ UFRRJ-Instituto de Biologia, BR 465, km. 7, 23.836-970, \\ Seropédica-RJ.
}

\begin{abstract}
RESUMO
As cultivares de jiloeiro (Solanum gilo) Tinguá, Comprido Verde Claro e Morro Redondo foram utilizadas em cruzamentos obedecendo a esquema dialélico, com os recíprocos. Os genitores e os respectivos híbridos $\mathrm{F}_{1}$ foram avaliados no campo, por 14 descritores fitotécnicos, dos quais sete foram estatisticamente analisados pelo Modelo de Griffing. Os genótipos demonstraram capacidade geral de combinação para comprimento, diâmetro e peso médio do fruto, número de dias até início da colheita e altura da planta. A capacidade específica de combinação, significativa para todas as características analisadas, indica efeitos de dominância e/ou epistáticos envolvidos no seu controle genético. Os híbridos 'Tinguá' x 'Comprido Verde Claro' e 'Comprido Verde Claro' x 'Morro Redondo' apresentaram resultados promissores para produção de frutos.
\end{abstract}

\begin{abstract}
Combining ability analysis in diallel crosses among three garden egg cultivars.

Three garden egg (Solanum gilo) cultivars: Tinguá, Comprido Verde Claro, and Morro Redondo were crossed in a diallel scheme including reciprocals. Parental cultivars and $\mathrm{F}_{1}$ hybrids were evaluated under field conditions in relation to 14 agronomic traits. Seven of these traits were statistically analysed and significant effects of general combining ability demonstrated for fruit length, fruit diameter, mean fruit weight, number of days from planting to initial harvesting, and plant height. With respect to specific combining ability there was significance for all characteristics analysed, showing that dominant/ epistatic effects were involved in their genetic control. The hybrids: 'Tinguá' x 'Comprido Verde Claro' and 'Comprido Verde Claro' $\mathrm{x}$ 'Morro Redondo' showed promising results for fruit yield.
\end{abstract}

Keywords: Solanum gilo, hybridization, yield.

\section{(Aceito para publicação em 18 de fevereiro de 2.002)}

$\mathrm{O}$ jiloeiro, Solanum gilo Raddi, é uma planta da família das solanáceas, com frutos de formas variadas, casca fina e coloração verde clara ou verde escura quando ainda imaturos, sendo apreciados por seu paladar e por suas propriedades digestivas (Castro, 1971). É bastante cultivado no Brasil, principalmente nos Estados do Rio de Janeiro, Minas Gerais, Espírito Santo e São Paulo (PESAGRO-RIO \& EMATER-RIO, 1989). No Rio de Janeiro encontra condições favoráveis ao seu cultivo, razão pela qual tem assumido importância crescente na olericultura fluminense. Em 1999, comercializaramse $14.305 \mathrm{t}$ de frutos, dos quais $98 \%$ provieram do Estado, com destaque para os municípios de Sumidouro, Nova Friburgo, Itaocara, Teresópolis e Cachoeiras de Macacu (CEASA-RJ, 2000).

No início dos anos 80 , eram poucas as cultivares de jiloeiro no comércio, sendo todas de origem nacional
(Filgueira, 1982), situação que parece perdurar até os dias de hoje. O mercado consumidor do Rio de Janeiro prefere frutos de coloração verde clara e formato alongado, enquanto em São Paulo têm maior aceitação aqueles arredondados e verde escuros.

O dialelo é um método genético-estatístico que auxilia na seleção de genitores, com base na capacidade de combinação relacionada à produtividade e outras características fitotécnicas em populações segregantes. O uso do dialelo permite, ainda, conhecer o controle genético dessas características, que orienta o método de melhoramento a ser adotado (Ramalho et al., 1993; Cruz \& Regazzi, 1994). Na análise dialélica proposta por Griffing (1956), o desempenho médio de cada genótipo é decomposto em capacidade geral de combinação (efeitos principais) e capacidade específica de combinação (interações). A capacidade geral de combinação
(CGC) diz respeito ao comportamento médio de um genitor numa série de combinações híbridas e está associada aos efeitos aditivos dos alelos e às ações epistáticas do tipo aditiva (Cruz \& Vencovsky, 1989). Por sua vez, a capacidade específica de combinação (CEC) é usada para estimar os desvios do comportamento de um híbrido em relação ao esperado com base na CGC, estando associada aos efeitos de dominância e epistasia (Cruz \& Vencovsky, 1989; Cruz \& Regazzi, 1994).

Poucos estudos genéticos têm sido realizados com o jiloeiro para subsidiar o melhoramento da espécie. Campos (1973) estudou o comportamento de oito variedades e de seus respectivos híbridos $F_{1}$, em cruzamentos dialélicos; estimou as diversas heteroses e procedeu à análise em látice, pesquisando correlações entre caracteres vegetativos e de produção; constatou a existência de alta CEC entre cruzamentos, recomendan-

${ }^{1}$ Parte de tese de doutorado do primeiro autor, apresentada ao Depto. De Genética da UFRRJ. 
Análise da capacidade combinatória em cruzamentos dialélicos de três cultivares de jiloeiro.

Tabela 1. Caracterização de três cultivares de jiloeiro (Solanum gilo), respectivos híbridos $\mathrm{F}_{1}$ e seus recíprocos, segundo sete descritores fitotécnicos. Seropédica-RJ, PESAGRO-RIO, 1997.

\begin{tabular}{|c|c|c|c|c|c|c|c|}
\hline \multirow{2}{*}{$\begin{array}{l}\text { Cultivarl } \\
\text { Híbrido }^{a}\end{array}$} & \multicolumn{7}{|c|}{ Descritor ${ }^{b}$} \\
\hline & CORFRU & CORPOL & CORCAL & FORCAL & FORFRU & FOREXT & FORSUP \\
\hline $\mathrm{T}$ & verde-clara & branca & verde & intermediário & ovalado & pontudo & intermediário \\
\hline CVC & verde-clara & branca & verde & intermediário & ovalado & pontudo & intermediário \\
\hline MR & verde-escura & branca & verde & intermediário & arredondado & obtuso & intermediário \\
\hline $\mathrm{T} \times \mathrm{CVC}$ & verde-clara & branca & verde & intermediário & ovalado & pontudo & intermediário \\
\hline $\mathrm{T} \times \mathrm{MR}$ & verde-escura & branca & verde & intermediário & arredondado & pontudo & intermediário \\
\hline$C V C \times T$ & verde-clara & branca & verde & intermediário & ovalado & pontudo & intermediário \\
\hline CVC $\times$ MR & verde-escura & branca & verde & intermediário & arredondado & pontudo & $\begin{array}{c}\text { levemente } \\
\text { lobado }\end{array}$ \\
\hline$M R \times T$ & verde-escura & branca & verde & intermediário & arredondado & pontudo & Intermediário \\
\hline$M R \times C V C$ & verde-escura & branca & verde & intermediário & arredondado & pontudo & $\begin{array}{l}\text { levemente } \\
\text { lobado }\end{array}$ \\
\hline
\end{tabular}

a $\mathrm{T}=$ 'Tinguá'; CVC = 'Comprido Verde Claro' e MR = 'Morro Redondo';

b (Fonte: Morgado \& Dias, 1992); CORFRU = cor do fruto imaturo; CORPOL = cor da polpa; CORCAL = cor do cálice; FORCAL = formato do cálice; FORFRU = formato do fruto; FOREXT = formato da extremidade apical do fruto; e FORSUP = formato da superfície do fruto.

do o uso de dialélicos na seleção de híbridos comerciais em jiloeiro.

O objetivo do presente trabalho foi estimar a CGC e a CEC em três cultivares de jiloeiro, selecionadas dentre as mais importantes atualmente no Brasil, utilizando a metodologia de cruzamentos dialélicos, com os recíprocos.

\section{MATERIAL E MÉTODOS}

Foram utilizadas plantas provenientes de sementes de jiloeiro cedidas pela Topseed Sementes Ltda., representando as cultivares Tinguá, Comprido Verde Claro e Morro Redondo. Os híbridos, obtidos através de polinização manual, obedeceram o esquema dialélico $3 \times 3$, com os recíprocos. Os cruzamentos foram efetuados em casa-de-vegetação na Estação Experimental de Itaguaí (EEI), da PESAGRO-RIO, sediada em Seropédica-RJ, no período de agosto a novembro de 1996. Foram usadas 10 plantas envasadas de cada cultivar, sendo que todas elas serviram como genitores femininos e masculinos. $\mathrm{O}$ pólen foi colhido de flores recém-abertas, previamente colocadas em placas de Petri por 24 horas para desidratar. Botões florais, no estádio anterior à antese, foram emasculados pela manhã e imediatamente polinizados.

Os seis híbridos $\mathrm{F}_{1}$ e as três cultivares genitoras foram avaliados na área experimental da EEI, no período de junho a dezembro de 1997. As parcelas foram constituídas de 10 plantas, dispostas no espaçamento de $1,5 \times 0,8 \mathrm{~m}$ entre linhas e entre plantas na mesma linha, respectivamente. Procederam-se os tratos culturais rotineiros, incluindo capinas, amontoa, irrigação por aspersão e pulverizações com pesticidas (quando necessário). Os frutos foram colhidos quando próprios para comercialização e logo colocados em sacos plásticos no refrigerador até que as avaliações fossem efetuadas. Essas avaliações basearam-se em alguns descritores para Capsicum (IBPGR, 1983) e berinjela (IBPGR, 1988), segundo Morgado \& Dias (1992). Foram avaliados a cor do fruto imaturo; cor da polpa; cor e formato marginal do cálice; formato do fruto; formato da extremidade do fruto; formato do fruto em corte transversal; número total e peso total de frutos; comprimento, diâmetro e peso médio do fruto; número de dias até início da colheita; e altura da planta.

Nas análises de capacidade combinatória foram incluídos os genitores e os híbridos $\mathrm{F}_{1}$, com os recíprocos, perfazendo o total de $\mathrm{p}^{2}$ genótipos; considerou-se o Modelo 1 (Griffing, 1956), supondo-se as cultivares como de efeito fixo e apenas o erro experimental como de efeito aleatório (Ramalho et al., 1993).

\section{RESULTADOS E DISCUSSÃO}

Os dados de cor do fruto (casca), da polpa e do cálice, de formatos do fruto intacto e em corte transversal, e de formatos marginal do cálice e da extremidade do fruto são apresentados na Tabela 1. Os três genitores e os respectivos híbridos $\mathrm{F}_{1}$ apresentaram polpa do fruto de cor branca, cálice verde e de formato marginal intermediário.

Quanto à cor do fruto (casca), observou-se dominância do verde escuro, que caracterizou todos os híbridos derivados da cultivar Morro Redondo. Campos (1973) constatou, também, que cultivares de jiloeiro de frutos verde-escuros transmitiam esta característica aos seus híbridos; além disso, verificou que os híbridos $F_{1}$ entre cultivares de frutos claros e escuros, apresentavam, de modo geral, listras mais claras entremeadas à cor escura da casca, o que foi confirmado no presente estudo.

Determinou-se, ainda, dominância da forma arredondada dos frutos, apresentada por todos os híbridos envolvendo 'Morro Redondo'.

Em relação ao formato da extremidade do fruto, detectou-se dominância da presença de "bico" apical (formato pontudo). Assim, os híbridos que tiveram como genitora a cultivar Morro Redondo, que produz frutos sem "bico", apresentaram-se pontudos. 
Quanto ao contorno superficial do fruto, todos os híbridos mostraram-se intermediários em relação aos genitores. Entretanto, os frutos dos híbridos derivados das cultivares Comprido Verde Claro e Morro Redondo exibiram perfil levemente lobado em corte transversal.

Embora trabalhando com cultivares diferentes, os resultados relativos a características de fruto assemelham-se também àqueles encontrados por Campos (1973), que não considerou, entretanto, alguns dos descritores presentemente estudados, tais como comprimento e diâmetro do fruto, cor da polpa, cor e formato do cálice.

Houve diferenças significativas entre os genótipos avaliados, permitindo a decomposição dos efeitos em CGC e CEC.

Quanto à CGC, registraram-se diferenças para peso, comprimento e diâmetro do fruto, número de dias até início da colheita, e altura da planta. Não foram detectadas diferenças para número e peso total de frutos (Tabela 2). Campos (1973) já havia constatado significância de quadrados médios referentes à CGC para a maioria das características por ele estudadas, indicando que as variedades de jiloeiro na ocasião utilizadas não constituíam, da mesma forma, um grupo geneticamente homogêneo.

Significância para CGC indica que efeitos gênicos aditivos estão envolvidos na herança de determinada característica. Esses efeitos gênicos aditivos são fixados ao longo de sucessivas gerações, sendo sobretudo importantes para espécies autógamas como o jiloeiro. A existência de efeitos gênicos aditivos para todos os descritores aqui avaliados abre a possibilidade de obtenção de novas cultivares a partir de cruzamentos com os genitores testados.

Altos valores de $\mathrm{g}_{\mathrm{i}}$ (positivos ou negativos) indicam divergências genéticas muito expressivas entre genitores. Assim, aqueles apresentando CGC elevada seriam potencialmente superiores quanto à sua contribuição em programas de melhoramento (Ramalho et al., 1993).

Pelos valores de $\mathrm{g}_{\mathrm{i}}$ referentes à produtividade (número e peso total de frutos), 'Tinguá' pode ser indicada como melhor genitora (Tabela 2).

Em termos de comprimento do fruto, a cultivar Morro Redondo apresentou valores negativos de CGC, contribuindo

Tabela 2. Efeitos $\left(\mathrm{g}_{\mathrm{j}}\right)$ da capacidade geral de combinação (CGC) com referência a sete descritores fitotécnicos, a partir de cruzamentos entre três cultivares de jiloeiro (Solanum gilo). Seropédica-RJ, PESAGRO-RIO, 1997.

\begin{tabular}{lccc}
\hline \multirow{2}{*}{ Descritor } & \multicolumn{3}{c}{ (CGC - gi) } \\
\cline { 2 - 4 } & $\mathbf{T}^{\mathrm{a}}$ & $\mathbf{C V C}$ & $\mathbf{M R}$ \\
\hline COMFRU $^{\mathrm{b}}$ & $0,04^{* *}$ & $0,22^{* *}$ & $-0,26 * *$ \\
DIFRU & $-0,07^{* *}$ & $-0,08^{* *}$ & $0,15^{* *}$ \\
NTF & 3,94 & $-0,71$ & $-3,24$ \\
PTF & 129,50 & $-78,83$ & 50,67 \\
PMF & $0,47^{* *}$ & $-0,97^{* *}$ & $-0,50 * *$ \\
NIC & $-4,01 * *$ & $2,77^{* *}$ & $1,25 * *$ \\
ALT & $-0,01 * *$ & $-0,03^{* *}$ & $0,04 * *$ \\
\hline
\end{tabular}

** Significativo ao nível de $1 \%$ pelo teste de Tukey;

a $\mathrm{T}=$ 'Tinguá'; $\mathrm{CVC}=$ 'Comprido Verde Claro'; $\mathrm{MR}=$ 'Morro Redondo';

${ }^{\mathrm{b}} \mathrm{COMFRU}=$ comprimento do fruto; DIAFRU = diâmetro do fruto; $\mathrm{NTF}=$ número total de frutos; $\mathrm{PTF}=$ peso total de frutos; $\mathrm{PMF}=$ peso médio do fruto; $\mathrm{NIC}=$ número de dias até início da colheita; ALT $=$ altura da planta.

Tabela 3. Efeitos $\left(\mathrm{s}_{\mathrm{ij}}\right)$ da capacidade específica de combinação (CEC) com referência a sete descritores fitotécnicos, a partir de cruzamentos entre três cultivares de jiloeiro (Solanum gilo). Seropédica-RJ, PESAGRO-RIO, 1997.

\begin{tabular}{|c|c|c|c|}
\hline \multirow{2}{*}{ Descritor } & \multicolumn{3}{|c|}{$\left(C E C-s_{i j}\right)$} \\
\hline & $T \times C V C^{a}$ & T X MR & CVC $\times$ MR \\
\hline COMFRU $^{\mathrm{b}}$ & 0,27 ** & $-0,25 * *$ & 0,33 ** \\
\hline DIFRU & $-0,16 * *$ & 0,06 ** & $-0,07 * *$ \\
\hline NTF & 14,67 ** & $-5,29 * *$ & $12,21 * *$ \\
\hline PTF & 362,33 ** & $-97,33 * *$ & $429,00 * *$ \\
\hline PMF & $-0,92 * *$ & 0,82 ** & 1,06 * * \\
\hline $\mathrm{NIC}$ & $-2,48 * *$ & $1,98 * *$ & $-7,45^{* *}$ \\
\hline ALT & 0,08 * * & $-0,03 * *$ & 0,06 ** \\
\hline
\end{tabular}

** Significativo ao nível de $1 \%$ pelo teste de Tukey;

a $\mathrm{T}=$ 'Tinguá'; $\mathrm{CVC}=$ 'Comprido Verde Claro'; $\mathrm{MR}=$ 'Morro Redondo';

${ }^{\mathrm{b}} \mathrm{COMFRU}=$ comprimento do fruto; DIFRU = diâmetro do fruto; NTF = número total de frutos; $\mathrm{PTF}=$ peso total de frutos; $\mathrm{PMF}=$ peso médio do fruto; $\mathrm{NIC}=$ número de dias até início da colheita; ALT = altura da planta.

para reduzir esse comprimento nos híbridos de que participou. 'Comprido Verde Claro' e 'Tinguá', por sua vez, contribuíram para aumentar o comprimento do fruto, destacando-se a primeira cultivar com os valores mais altos.

'Comprido Verde Claro' e 'Tinguá', ambas produzindo frutos ovalados, induziram valores negativos de $\mathrm{g}_{\mathrm{i}}$, demonstrando seu potencial de reduzir o diâmetro do fruto nos cruzamentos em que estiverem envolvidas. Ao contrário, 'Morro Redondo', que produz frutos do tipo arredondado, contribuiu no sentido de aumentar o diâmetro.

Com relação ao ciclo, 'Tinguá', enquanto genitor, influenciou na diminui- ção do número de dias até início da colheita, enquanto 'Comprido Verde Claro' e 'Morro Redondo' revelaram efeito oposto.

Finalmente, no que concerne à altura (porte) da planta, somente a cultivar Morro Redondo apresentou valores positivos de $\mathrm{g}_{\mathrm{i}}$, sendo a única, desse modo, a contribuir para aumentá-la.

Os efeitos relacionados à CEC $\left(s_{i j}\right)$ foram significativos para todos os descritores avaliados (Tabela 3). Valores de baixa magnitude indicam que os híbridos $\mathrm{F}_{1}$ entre as cultivares parentais apresentaram comportamento esperado, com base na CGC. Por outro lado, altos valores de $\mathrm{s}_{\mathrm{ij}}$ indicam que o desempe- 
nho de um dado híbrido tenderá a ser melhor ou pior, em relação ao esperado por conta da CGC dos genitores.

Valores de $s_{i j}$ negativos foram registrados no cruzamento 'Tinguá' $\mathrm{x}$ 'Morro Redondo' para produtividade (número e peso total de frutos). As demais hibridações caracterizaram-se por valores positivos de $\mathrm{s}_{\mathrm{ij}}$, com os $\mathrm{F}_{1}$ 's 'Tinguá' x 'Comprido Verde Claro' e 'Comprido Verde Claro x 'Morro Redondo' destacando-se quanto a número e peso total de frutos, respectivamente.

No conjunto das características estudadas, o cruzamento 'Comprido Verde Claro' $x$ 'Tinguá' revelou $65 \%$ de heterose em relação à média dos pais e $32 \%$ em relação à do genitor mais produtivo, para número total de frutos; $63 \%$ de heterose em relação à média dos pais e $30 \%$ em relação à do genitor mais produtivo, quanto ao peso total de frutos (Tabela 3).

Quanto ao diâmetro do fruto, apesar do $\mathrm{F}_{1}$ 'Comprido Verde Claro' $\mathrm{x}$ 'Tinguá' ter apresentado heterose negativa, a característica é desejável para atender à preferência dos consumidores cariocas por frutos mais compridos.
Esse mesmo híbrido produziu frutos de padrão adequado à comercialização no Estado do Rio de Janeiro, isto é, de coloração verde clara, formato ovalado e "bico" apical, além de revelar maior precocidade do que seus genitores.

\section{AGRADECIMENTOS}

Ao pesquisador Marco Antonio de Almeida Leal (PESAGRO-RIO/EEI) pelas sugestões e apoio nas análises estatísticas, e à Fundação de Amparo à Pesquisa do Estado do Rio de Janeiro (FAPERJ) pelo auxílio financeiro.

\section{LITERATURA CITADA}

CAMPOS, J.P. Aspectos teóricos e aplicados da heterose em jiló (Solanum gilo Raddi). Piracicaba: ESALQ, 1973. 88 p. (Tese doutorado).

CASTRO, A.G. Cultura do jiló (Solanum gilo Raddi). A Lavoura, v. 74, p. 5, 1971.

CENTRAIS DE ABASTECIMENTO DO RIO DE JANEIRO (CEASA-RJ) - SPD - Evolução histórica das quantidades por produto: grupo-hortaliças, subgrupo-fruto, produto-jiló, período 1990-1998. Rio de Janeiro: CEASA/GRANDE RIO, 2000. n.p.
CRUZ, C.D.; REGAZZI, A.J. Modelos biométricos aplicados ao melhoramento genético. Viçosa: Imprensa Universitária, 1994. 390 p. CRUZ, C.D.; VENCOVSKY, R. Comparação de alguns métodos de análise dialélica. Revista Brasileira de Genética, Ribeirão Preto, v. 12, n. 2, p. 425-438, 1989.

EMPRESA DE PESQUISA AGROPECUÁRIA DO ESTADO DO RIO DE JANEIRO, Niterói, RJ; EMPRESA DE ASSISTÊNCIA TÉCNICA E EXTENSÃO RURAL DO ESTADO DO RIO DE JANEIRO, Niterói, RJ. Recomendações para a cultura do jiló. Niterói, 1989. 16 p. (PESAGRORIO/EMATER-RIO. Informe Técnico, 18).

FILGUEIRA, F.A.R. Solanáceas III: pimentão, pimentas, berinjela e jiló. In: FILGUEIRA, F.A.R., ed. Manual de olericultura: cultura e comercialização de hortaliças. São Paulo: Agronômica Ceres. v. 2, 1982. p. 301-318.

GRIFFING, B. Concept of general and specific combining ability in relation to diallel crossing systems. Australian Journal of Biological Science, v. 9, p. 463-493, 1956.

MORGADO, H.S.; DIAS, M.J.V. Caracterização da coleção de germoplasma de jiló do CNPH/ EMBRAPA. Horticultura Brasileira, Brasília, v. 10, n. 2, p. 86-88, 1992

RAMALHO, M.A.P.; SANTOS, J.B.; ZIMMERMANN, M.J.O. Genética quantitativa em plantas autógamas; aplicações ao melhoramento do feijoeiro. Goiânia: Editora da UFG, 1993. $271 \mathrm{p}$. 